\title{
Hesse, Jan-Otmar, Wirtschaft als Wissenschaft. Die Volkswirtschaftslehre in der frühen Bundesrepublik
}

Jean Solchany

\section{OpenEdition}

\section{Journals}

Édition électronique

URL : http://journals.openedition.org/ifha/6723

DOI : 10.4000/ifha.6723

ISSN : 2198-8943

Éditeur

IFRA - Institut franco-allemand (sciences historiques et sociales)

\section{Référence électronique}

Jean Solchany, « Hesse, Jan-Otmar, Wirtschaft als Wissenschaft. Die Volkswirtschaftslehre in der frühen Bundesrepublik », Revue de l'IFHA [En ligne], Date de recension, mis en ligne le 01 janvier 2012, consulté le 22 septembre 2020. URL : http://journals.openedition.org/ifha/6723 ; DOI : https://doi.org/10.4000/ ifha. 6723

Ce document a été généré automatiquement le 22 septembre 2020.

(C)IFHA 


\title{
Hesse, Jan-Otmar, Wirtschaft als Wissenschaft. Die Volkswirtschaftslehre in der frühen Bundesrepublik
}

\author{
Jean Solchany
}

1 La pensée économique allemande est inégalement étudiée. Dominante jusqu'au début du XXe siècle sous la houlette de Gustav Schmoller, décriée ensuite pour son historicisme jugé rétrograde, redécouverte ces dernières années, l'école historique allemande a déjà fait l'objet d'un nombre relativement important de travaux. Sur les débuts de la République fédérale allemande, en revanche, période pendant laquelle il est moins évident d'identifier une tendance dominante, les études sont moins nombreuses. C'est tout le mérite de J.-O.H. que de proposer une réflexion d'ensemble sur les mutations de la science économique allemande de l'immédiat après-guerre au milieu des années 1970.

2 S'il refuse de souscrire au constat partiellement simplificateur de la modernisation d'une pensée économique allemande rattrapant son retard sur le monde anglo-saxon, l'auteur n'en met pas moins en évidence l'ampleur des changements survenus. Les échanges accrus avec les États-Unis, le rôle des fondations philanthropiques américaines, le développement de l'économétrie, la diffusion de la synthèse néoclassique, la montée en puissance des instituts de recherche économique extrauniversitaires, le poids croissant des économistes et de leur expertise technocratique dans les débats médiatiques et politiques participent de l'affirmation d'une science économique qui, au début des années 1970, a définitivement tourné le dos à l'historicisme. Selon J.-O.H., la principale évolution sur le plan théorique réside moins dans la réception du keynésianisme que dans l'affirmation d'une micro-économie néoclassique.

3 Les bouleversements que connaît l'université allemande en un laps de temps réduit ont également contribué au changement. L'expansion accélérée qui résulte de l'accroissement considérable des moyens dévolus à la formation, dont témoigne leur forte progression dans le PIB d'une économie ouest-allemande qui enregistre en outre 
une forte croissance, coïncide avec le départ de la vieille génération des économistes encore en poste ou réintégrés après une période de mise à l'écart et voit le nombre de chaires augmenter considérablement. Le rattachement traditionnel de l'économie au droit est également mis en question avec la mise en place à la fin de la période de facultés de sciences économiques. Dans les universités souvent en pénurie de relève interne, ce changement d'échelle qui induit une spécialisation accrue s'accompagne du recrutement de nombreux économistes qui ont d'abord exercé une activité de recherche dans les instituts de recherche privés.

Mutations paradigmatiques et structurelles vont donc de pair au fil d'une analyse qui a le souci de la nuance. J.-O.H. souligne avec raison que le poids de l'ordolibéralisme ne doit pas être surestimé dans sa capacité à peser dans le champ académique, surtout après la disparition prématurée, en 1950, de ses deux principaux représentants, Walter Eucken et Leonhard Miksch. Il observe également la relative diversité des approches qui prévaut encore au lendemain de 1945, remarquant au passage que même aux ÉtatsUnis, en dehors de Chicago, Harvard ou Cambridge, la plupart des enseignements ne recourent pas à la formalisation mathématique avant la fin des années 1950. Dans le cas ouest-allemand, les développements sur l'autoreprésentation de la discipline, les débats internes sur sa réorganisation et le rôle déclinant du Verein für Socialpolitik permettent de saisir la redéfinition progressive de l'identité de la science économique, la manière même de la désigner faisant alors débat. Enfin, l'étude des recrutements pratiqués par les universités de Bonn, Francfort et Tübingen, retenues comme études de cas, invite à mesurer, au ras des renouvellements de postes, la part de contingence et de préoccupations extra-scientifiques qui préside également à l'évolution des facultés. On regrettera simplement le caractère parfois excessivement pointilliste de certaines analyses, - le lecteur ayant souvent tendance à perdre le fil -, qui alourdit quelque peu une étude par ailleurs tout à fait passionnante.

5 Jean Solchany (IEP de Lyon) 